\title{
Casa, solar e palácio: Técnicas de restauração em madeira
}

Marisa Hoirisch*, Rosina Trevisan M. Ribeiro**

\section{Resumo}

Este artigo descreve e analisa ações de restauração e conservação adotadas na salvaguarda de estruturas em madeira de três edificações históricas, erigidas no século 19, na cidade do Rio de Janeiro. São prédios com características tipológicas distintas, cujas intervenções ocorreram de 1996 a 2005. Trata-se de uma casa, um solar e um palácio: respectivamente, o Museu Villa-Lobos, o Solar da Marquesa de Santos e o Palácio Universitário da Universidade Federal do Rio de Janeiro (UFRJ) todos tombados pelo Instituto do Patrimônio Histórico e Artístico Nacional (IPHAN), em função de seus valores históricos e artísticos. Apresenta-se um breve relato da história e arquitetura destes três monumentos, e na sequência são descritas as intervenções utilizadas na restauração de suas estruturas. O objetivo é demonstrar as estratégias diferenciadas que foram utilizadas para a conservação de distintos sistemas estruturais.

Palavras-chave: Restauração de madeiras. Preservação de prédios históricos, século 19, Rio de Janeiro, RJ, Brasil.

House, manor and palace: Wood restoration techniques

\section{Abstract}

This paper describes and analyses the restoration and conservation interventions in the roof wooden structures of three historical buildings erected in the $19^{\text {th }}$ Century, in the city of Rio de Janeiro. These interventions took place between 1996 and 2005, in buildings with different typological features: a house, a manor and a palace respectively, Villa-Lobos Museum, Marquesa de Santos Manor and the University Palace of Universidade Federal do Rio de Janeiro -, all listed for their historical and artistic values by Instituto do Patrimônio Histórico e Artístico Nacional (IPHAN), the Brazilian Historic and Artistic Heritage. A brief historical report is presented, followed 
by descriptions of the interventions undertaken in each structure. The aim was to show the various strategies that were applied to preserve different structural systems.

Key-words: Wood protection techniques. Wood preservation in historical buildings, Rio de Janeiro, RJ, Brazil.

\section{Introdução}

Do conjunto de monumentos históricos construídos no século 19 na cidade do Rio de Janeiro, três edificações foram destacadas para estudo: a Casa do Museu VillaLobos, o Solar da Marquesa de Santos e o Palácio Universitário. A seleção destes bens imóveis tombados se deu pelas diferentes técnicas adotadas na restauração de suas estruturas de madeira.

Esta pesquisa apresenta a história e arquitetura destes três monumentos, abordando na sequência as ações de intervenção empreendidas em suas estruturas de madeira. Estuda a práxis das intervenções realizadas e discute as razões que determinaram a eleição das ações restaurativas empreendidas em cada um destes monumentos.

\section{Museu Villa-Lobos}

O sobrado foi tombado em 1967, e está localizado na Rua Sorocaba, $n^{\circ} 200$, no bairro de Botafogo, Rio de Janeiro Apontado como exemplar característico da arquitetura residencial urbana do final do século 19, integra um conjunto que abrange outras duas casas, situadas na vizinhança.

Fundado em 1961, o Museu Villa-Lobos (FIGURA 01) preserva e divulga um valioso acervo, constituído por partituras originais, fotografias e objetos, que testemunham a vida e obra do grande compositor e maestro brasileiro que the empresta o nome. Situado atualmente numa casa cuja construção data de 1868, sua reforma em 1892 confere-lhe um segundo pavimento, além de imponente fachada. Este casarão ostenta elevado pé-direito, assoalhos decorados em parquet e pinturas decorativas nos forros e sancas. No térreo, situado no centro da fachada, há um pórtico de cantaria com arcos que, em seu topo, compõe uma varanda. O sobrado exibe 
pilastras de ordem coríntia e vãos com guarnições e sobrevergas de esmerados ornatos, trazendo, sobre a cimalha, platibanda vazada com acrotério finamente decorado ao centro. No exterior há um busto de Villa-Lobos e um anfiteatro, onde se realizam concertos.

\subsection{Restauração da estrutura do telhado da casa}

O telhado do Museu Villa-Lobos não é original: todo ele foi substituído para a introdução de um segundo pavimento, ainda em 1892. Sua estrutura consiste em tesouras de madeira, que, devido a infiltrações oriundas da má conservação do telhado, passaram a apresentar em algumas regiões alto teor de umidade, o que estimulou $\mathrm{o}$ ataque de cupins. Em alguns casos, estas peças de madeira passaram a apresentar canalículos, galerias ou frestas, o que comprometia sua função estrutural.

Após uma criteriosa avaliação, as madeiras foram assim classificadas:

a. Peças íntegras a serem mantidas. As peças consideradas em perfeito estado de conservação receberam tratamento de combate a cupins.

b. Peças afetadas:

- b.1 Inaproveitáveis: As vigas de madeira, por não mais exercerem sua função estrutural, foram retiradas do local;

- b.2 A serem preservadas: Puderam ser assim consideradas, após o tratamento contra xilófagos.

As peças não aproveitáveis foram substituídas por outras, de igual dimensão e seção. Neste caso, estas madeiras novas foram secas em estufa e posteriormente receberam um tratamento contra cupins, orientado por biólogos especializados em pragas urbanas.

A manutenção das peças atacadas por xilófagos só foi possível graças ao adequado preenchimento de suas cavidades. Sendo um monumento tombado, a intervenção foi toda orientada pelo IPHAN, que optou pela adoção das seguintes medidas: 
a. Limpeza e preparo das cavidades, com aspiração, para remoção de detritos, poeira e serragem;

b. Colocação de formas de compensado em ambos os lados da peça de madeira, para impedir que a mistura escorresse da cavidade a ser obturada;

c. Preparo, à parte, em balde de plástico, de uma mistura constituída por resina epoxídica líquida e areia (FIGURA 02);

d. Obturação das cavidades com a mistura do item anterior, com colher de pedreiro e alisamento da superfície com espátula (FIGURA 03);

e. Cura do material que serviu para a obturação das cavidades e retirada das formas de compensado.

\section{Solar da Marquesa de Santos}

O monumento que abriga desde 1979 o Museu do Primeiro Reinado (FIGURA 04) situa-se na Avenida Pedro II, $n^{\circ} 283$, no bairro carioca de São Cristóvão e consta do Livro de Tombo do IPHAN como Solar da Marquesa dos Santos.

Em 1824, o imóvel foi adquirido por D. Pedro I para a Marquesa de Santos (1). Neste solar foram realizadas obras até 1827, baseadas no projeto de Pedro José Pézerat; pinturas decorativas ficaram a cargo de Francisco Pedro do Amaral e a Marc Ferrez coube a ornamentação dos estuques. Grandes reformas lhe conferem a feição neoclássica, típica de nobres residências no século 19. A Marquesa se instala nesta imponente construção em 1828, mas de lá se transfere após novo matrimônio do Imperador que, na sequência, o doa a uma de suas filhas. O Barão de Mauá foi apenas um de seus inúmeros proprietários. No século 20 , o solar sedia o Serviço Nacional de Febre Amarela e é declarado de utilidade pública. Em 1965, por determinação do Governador Lacerda, uma restauração recupera-lhe os afrescos primitivos.

O prédio assobradado, de linhas neoclássicas, frente de rua, influência da escola francesa, possui bandas e ombreiras de cantaria. Molduras sobre vergas aplicadas como simples ornato. Entablamento com frisa ornada. Platibanda e falsos frontões com seus campos ornados. Pilastras jônicas e vasos de mármore sobre a platibanda. Na fachada lateral, tímpano com alegoria da deusa Minerva e folhas de acanto em relevo no medalhão central. A fachada de fundo é considerada atributo neoclássico dos mais nítidos e puros construídos no Rio de Janeiro. (LIVRO de Tombo, do Iphan, 2008). 
Seu tombamento em 1938, apenas quatro meses após a criação do IPHAN (2), não chega a surpreender, quando se considera seu elevado valor histórico e artístico.

Em seu uso atual como Museu do Primeiro Reinado, exibe um acervo que inclui móveis, pinturas e objetos de arte que apresentam, em seus salões decorados e refinados, os ambientes e o modus vivendi da nobreza brasileira no século 19.

\subsection{Restauração das estruturas do telhado do solar}

O telhado do Solar da Marquesa de Santos é composto por múltiplos panos formados por telhas coloniais, que despejam as águas pluviais em calhas (FIGURA 05). A cobertura é toda oculta por platibandas de alvenarias caiadas, contornando todo o perímetro do monumento, encimado por telhas, além de uma sequência de vasos brancos em mármore. $\mathrm{Na}$ cobertura, para substituir estes elementos cerâmicos quebrados ou rachados e varrer as calhas, é possível transitar por placas de concreto, evitando-se, assim, danos ao telhado. A má vedação desta cobertura em alguns períodos anteriores ocasionou infiltrações no madeiramento que compõe sua estrutura.

A técnica de sustentação do telhado inclui uma bela e complexa estrutura em formato de 'guarda-chuva' composta por 'varas', que são peças de madeira inclinadas que partem da peça central e se fixam por encaixe e amarrações de aço a peças horizontais e também ao eixo vertical, designado 'haste'. É interessante notar que as hastes centrais se fixam à cumeeira, mas não se apóiam no forro do solar, permanecendo suspensas. Este aspecto teve que ser levado em conta ao se estudar uma ação restaurativa no telhado. Após o controle de cupins no madeiramento por meio de injeções de preservativos e iscas, foram inseridos berços de aço no 'cabo' das hastes dos guarda-chuvas e novos grampos em aço, com a finalidade de conferir uma maior rigidez ao conjunto estrutural. Foi todo em aço o reforço estrutural feito neste solar (FIGURA 06).

\section{Palácio Universitário}

O monumento arquitetônico sito à Avenida Pasteur, $n^{\circ} 250$, na Urca, é uma das construções mais emblemáticas do neoclássico da antiga capital do Império luso. Conforme Marques dos Santos (2004, p.10), a localização deste suntuoso palácio 
junto à Baía de Guanabara simbolizava aos que aportavam no Rio de Janeiro um marco civilizatório do Império.

O prédio que hoje abriga o Palácio Universitário da UFRJ é um monumento histórico: foi concebido para ser o Hospício de Pedro II, numa iniciativa pioneira de se proporcionar um tratamento humanitário aos alienados no Brasil. Foi erguido de 1842 a 1852, para celebrar a maioridade deste monarca. O projeto arquitetônico coube a Domingos Monteiro, mas o pórtico, frontão neoclássico e capela ficaram a cargo de José Maria Jacinto Rabelo e Joaquim Cândido Guillobel. Seu nome é mudado para Hospício Nacional de Alienados, após a Proclamação da República. Com a transferência dos loucos em 1944, o prédio fica inicialmente vazio, tendo sido cogitado outro uso (3), e até mesmo sua demolição. Em 1948 este palácio foi cedido à UFRJ, e sua adaptação e restauração foram empreendidas pelo então reitor Pedro Calmon. Assim, suas instalações passaram a abrigar algumas unidades acadêmicas da Universidade Federal do Rio de Janeiro.

Sua fachada é marcada pela horizontalidade, tendo suas paredes brancas caiadas 0 destaque de um pórtico, encimado por frontão neoclássico todo revestido por cantaria, em gnaisse bege. Os corredores internos ligam as salas aos pátios e possuem painéis de azulejos portugueses. Os salões nobres ostentam pilastras que compartimentam as paredes, e estuques nos tetos que se articulam com a escadaria nobre e a capela.

Originalmente havia quatro pátios internos circundados por arcos, lembrando os antigos claustros. Em torno deles desenvolvem-se galerias azulejadas, amplas, bem ventiladas e iluminadas. A partir de 1904, o palácio passa a apresentar sua configuração atual, quando the são acrescidas duas áreas em $U$ e a consequente criação de mais dois pátios internos (FIGURA 07).

A simetria das plantas, com repetição dos dois lados do eixo central, com as galerias se destacando na composição e modulações marcando o ritmo das fachadas, segue os padrões de projetação de Durand, criando harmonia de formas e enaltecendo a horizontalidade deste conjunto. 


\subsection{Restauração das estruturas do palácio}

Dentre as características arquitetônicas desta edificação, há belíssimos salões com fina ornamentação de paredes, tetos e esquadrias. Seus pisos no segundo e terceiro pavimentos consistem em extensas tábuas corridas fixadas com pregos de forja em barrotes de madeira. Estes tabuados apresentam, mesmo hoje, boa fixação na estrutura do piso, a não ser nos casos em que as madeiras das vigas sofreram degradação, pelo ataque de cupins, brocas e fungos. Três salões, totalizando área em torno de $290 \mathrm{~m}^{2}$, tiveram seus pisos prospectados e, após uma avaliação de sua resistência e deformabilidade, engenheiros de estruturas verificaram que parte de suas vigas teria que ser reforçada ou substituída, em função dos ataques de cupins no madeiramento (FIGURA 08).

Em dois destes espaços, Salão Dourado e gabinete da Coordenação do Fórum de Ciência e Cultura, optou-se pela substituição das vigas, cujas seções estavam reduzidas, por outras novas de igual dimensão, com 10" x 10" de seção. Para possibilitar a realização da manobra desses barrotes, que chegavam a atingir até 9,10m de comprimento e garantir sua remoção, foi necessário escavar as paredes onde se apoiavam de cada um de seus lados. Após o tratamento contra cupins, novas vigas foram inseridas, com o cuidado prévio de verificar que as peças estivessem secas e tratadas contra insetos xilófagos. Na vedação das cavidades das alvenarias de pedra, utilizou-se grout de preenchimento, composto por cimento, areia e água. Este procedimento moderno teve como objetivo assegurar que a parede continuasse exercendo sua função estrutural. Isto porque, neste palácio, o piso em tábuas corridas tem sua sustentação feita por vigas de madeira que se apóiam nas paredes, constituindo um conjunto estrutural integrado, isto é, as vigas são embutidas nas paredes, não podendo ser retiradas sem acarretar queda da resistência das paredes.

Num terceiro espaço deste palácio, Secretaria da pós-graduação da Faculdade de Educação, empregou-se outro procedimento. As vigas afetadas por ataques de cupins, consideradas aptas a serem preservadas, foram mantidas, e introduzidas duas vigas de reforço de 3" x 9", num sistema designado "sanduíche" (FIGURA 09). O objetivo, neste caso, foi reduzir o tempo de execução da obra e também minimizar gastos, já que, com a opção pelo emprego de barrotes com seção disponível no 
mercado, o custo cairia. No preenchimento das cavidades das alvenarias para a inserção destas vigas extras também foi empregado grout.

\section{Conclusões}

Primeiramente é importante esclarecer que, mesmo tendo sido perguntado, em nenhum dos casos pesquisados foi esclarecido o porquê da decisão da utilização da técnica empregada para restauro das respectivas estruturas de madeira em detrimento de qualquer outra possibilidade.

Estando as peças de madeira da estrutura do telhado do Solar da Marquesa de Santos em relativo bom estado, foi adequada a decisão de se aumentar a rigidez por meio de amarrações e reforços em aço. Assim, ficou bem demarcada a intervenção, o que é desejável e recomendável quando se trata de recuperar as estruturas de um bem cultural.

$\mathrm{Na}$ análise da obra de recuperação das estruturas de madeira que suportam o telhado da casa de Villa-Lobos, impediu-se a deterioração do monumento original, com a adoção de uma técnica de restauração moderna. Adverte-se para o fato de que o material utilizado no reforço de estruturas de madeira pode ser considerado ainda em fase de testes. Seu emprego é amplamente difundido na obturação de trincas de estruturas em concreto armado, mas não houve tempo suficiente para avaliar seu desempenho na vedação de cavidades de peças de madeira a médio e longo prazo. O que se pode afiançar é que três quesitos puderam ser cumpridos:

a. Garantiu-se a manutenção da resistência original desta estrutura.

b. Ficou bem demarcada a intervenção. Assim, quando este monumento for analisado no futuro, sempre ficará evidente a inserção da resina numa fase posterior à da obra original.

c. Por minimizar o corte de árvores, promoveu-se uma restauração baseada na sustentabilidade ambiental.

No caso das estruturas de madeira que sustentam os pisos do Palácio Universitário da UFRJ, optou-se pelo uso de vigas do mesmo material e dimensões empregadas na construção original no caso de dois ambientes. A introdução de um procedimento 
moderno como o grout objetivou preservar a resistência destas alvenarias de pedra argamassada. Esta intervenção restaurativa teve como finalidade deter o avanço da destruição das estruturas do piso a partir do momento em que a intervenção foi realizada. Os benefícios desta ação foram, além da salvaguarda do edifício, a garantia da segurança e trânsito no local.

Esta pesquisa apresentou as técnicas e materiais distintos inseridos nas intervenções de três prédios. Ao serem realizadas estas obras, não foram elaboradas pesquisas das intervenções anteriormente empreendidas nos monumentos. Seu interesse está na ousadia de mesclar novos materiais aos originais da edificação, possibilitando-se distinguir estes dos que foram inseridos a posteriori, atendendo com isto, o critério de distinguibilidade da intervenção realizada. Tal procedimento atende também aos critérios de intervenção ditados nas Cartas Patrimoniais, como citado na Carta de Veneza, Art. 10, quando diz que

a consolidação do monumento pode ser assegurada com o emprego de todas as técnicas modernas de conservação e construção cuja eficácia tenha sido demonstrada por dados científicos e comprovada pela experiência. (CURY, 2000, p. 93).

As técnicas de restauração empregadas nos três monumentos foram especificadas por engenheiros especializados, após avaliação técnica, e aprovadas pelo órgão de preservação competente - IPHAN - garantem a resistência física e mecânica necessária ao seu funcionamento. Porém, deveriam ficar registrados - e disponibilizados para consulta pública - os critérios que subsidiaram as decisões tomadas, especialmente porque, como se viu, nos três casos foram empregados procedimentos bastante diferentes entre si. No entanto, não foi possível saber as razões das decisões tomadas, embora, certamente, tenham sido levados em conta fatores como a porcentagem de peças danificadas em cada caso, e os custos dos diferentes procedimentos passíveis de serem utilizados.

Quanto à escolha das técnicas empregadas em cada um dos exemplares estudados, verifica-se que no Solar da Marquesa a colocação de peças metálicas era o sistema mais adequado para o reforço da estrutura em "guarda-chuva" do telhado, não descaracterizando a mesma e deixando claro o material inserido. 
Quanto ao Palácio Universitário, que utilizou o sistema de "sanduíche" nos barrotes de piso, na época da intervenção (1995) ainda não era usual e não tinha sido testada a aplicação de resina epoxídica. Já na Casa de Vila Lobos, em 2005, esta era uma das técnicas mais modernas empregada em reforço de estruturas de madeira danificada. Como pode ser visto, optou-se por técnicas que garantissem o desempenho físico e mecânico das estruturas e que ficasse claro tratar-se de uma intervenção compatível com a época executada, mostrando a diferenciação do original e evitando-se, com isto, interpretação errônea de identificação no futuro, que poderia gerar um falso histórico.

Quando da realização da pesquisa, em 2008, que gerou este artigo, os monumentos em questão foram vistoriados e as intervenções realizadas apresentavam bom desempenho físico. As vigas de madeira do Palácio Universitário não puderam ser verificadas de forma adequada pois seria necessária a retirada do piso das salas que sofreram as intervenções, no entanto estas não apresentavam nenhum sinal de patologia, tais como presença de cupim e instabilidade.

O emprego de técnicas e materiais modernos deve, no entanto, ser discutido e avaliado, principalmente no que tange aos encaixes de madeira. No caso de serem substituídos por técnicas modernas, arriscariam a perda da memória de uma técnica construtiva executada em uma determinada época, como nos casos em que se opta por substituir toda a estrutura de madeira por aço visando evitar deterioração futura devido ao ataque dos xilófagos, a qual pode ser evitada pela manutenção periódica do madeiramento.

É importante deixar claro que não existe um procedimento único de intervenção. Deve-se avaliar o mais adequado a cada caso, visando a preservação do patrimônio edificado, não se esquecendo da importância de se preservar a técnica construtiva original como parte da história de uma edificação. 


\section{Imagens}

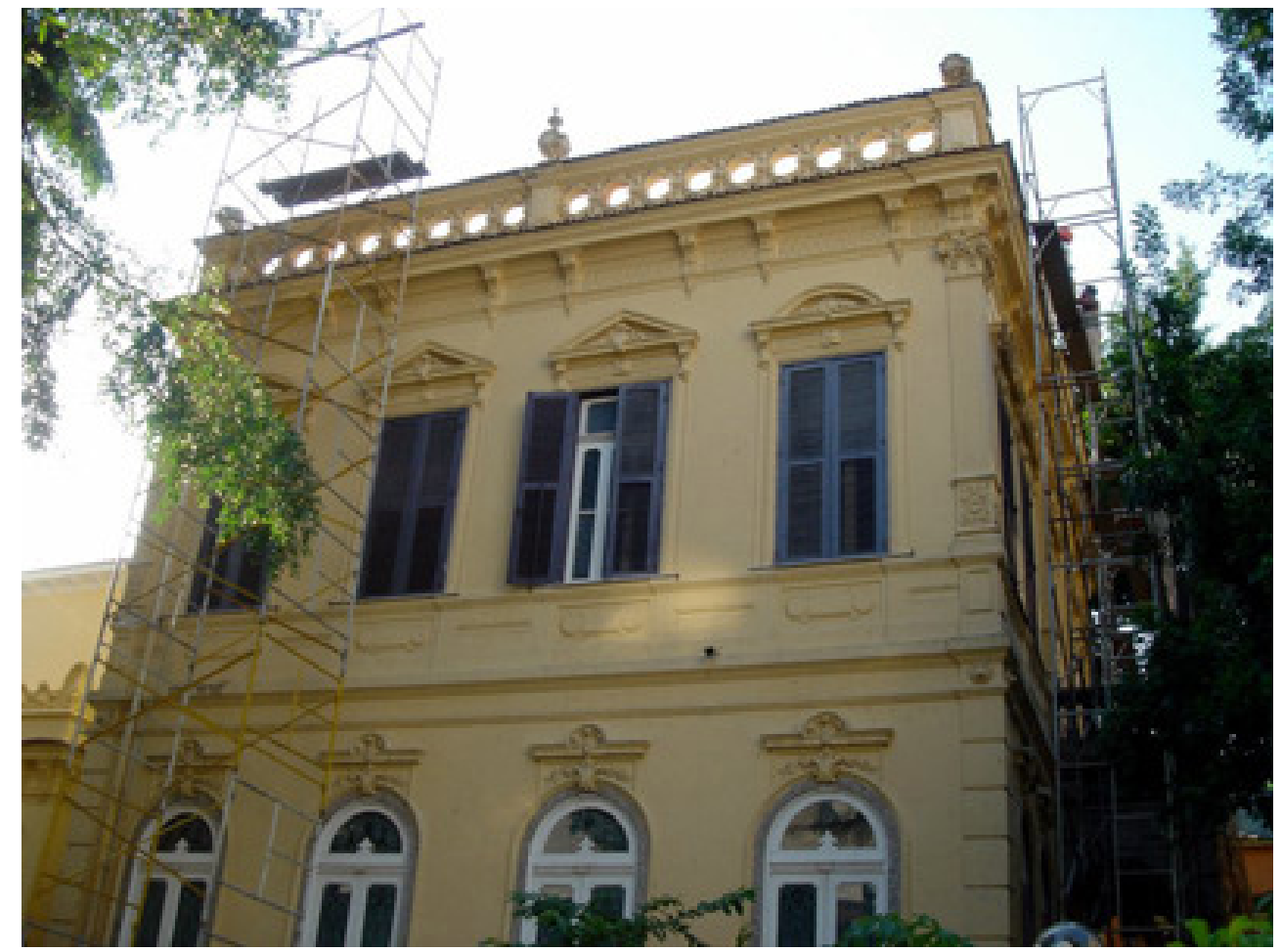

FIGURA 01 - Museu Villa-Lobos, fachada principal.

Fonte:http://www.museuvillalobos.org.br/

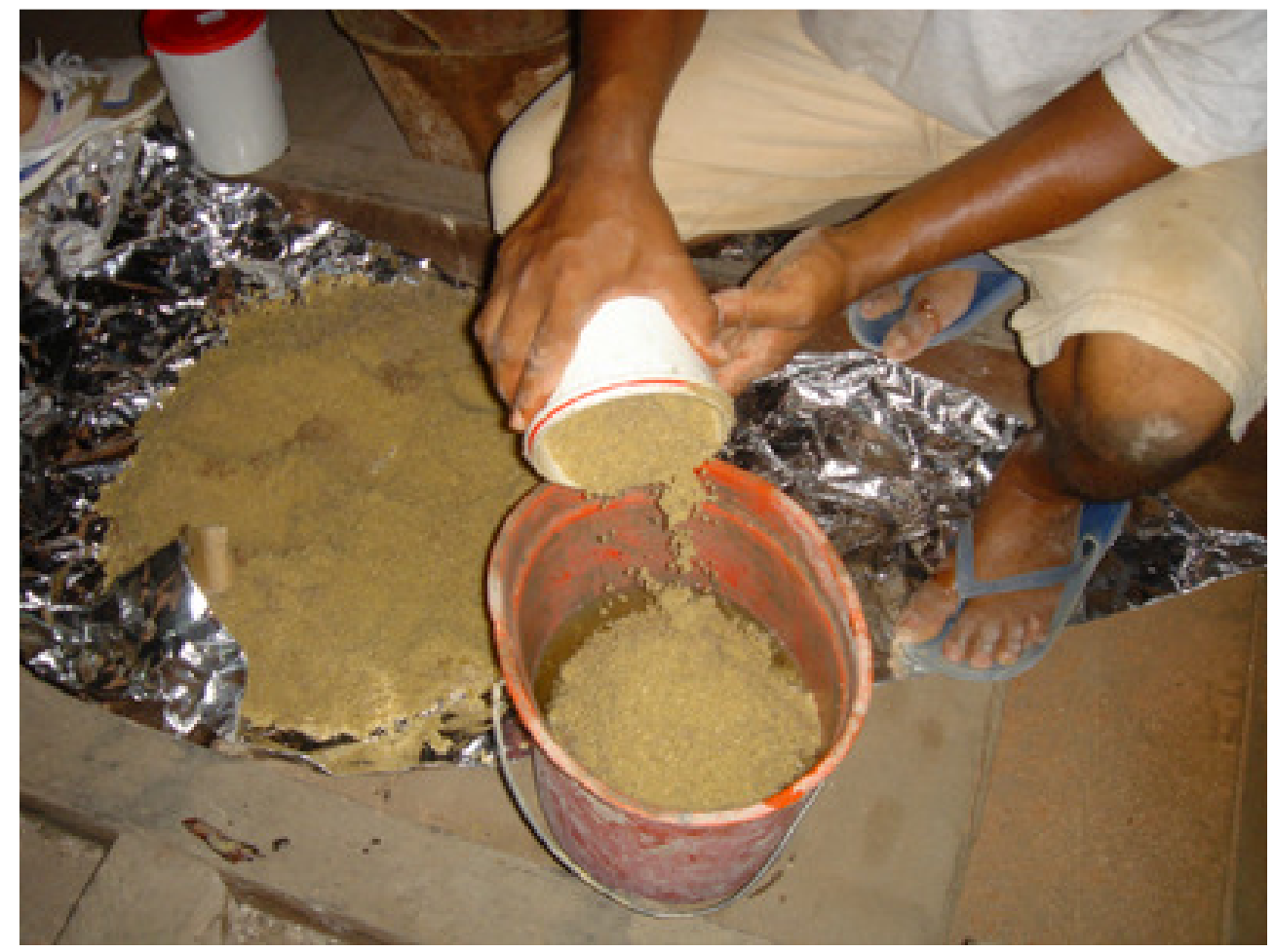

FIGURA 02 - Preparo de resina, Museu Villa-Lobos. Fotografia de Marisa Hoirisch, 2005. 


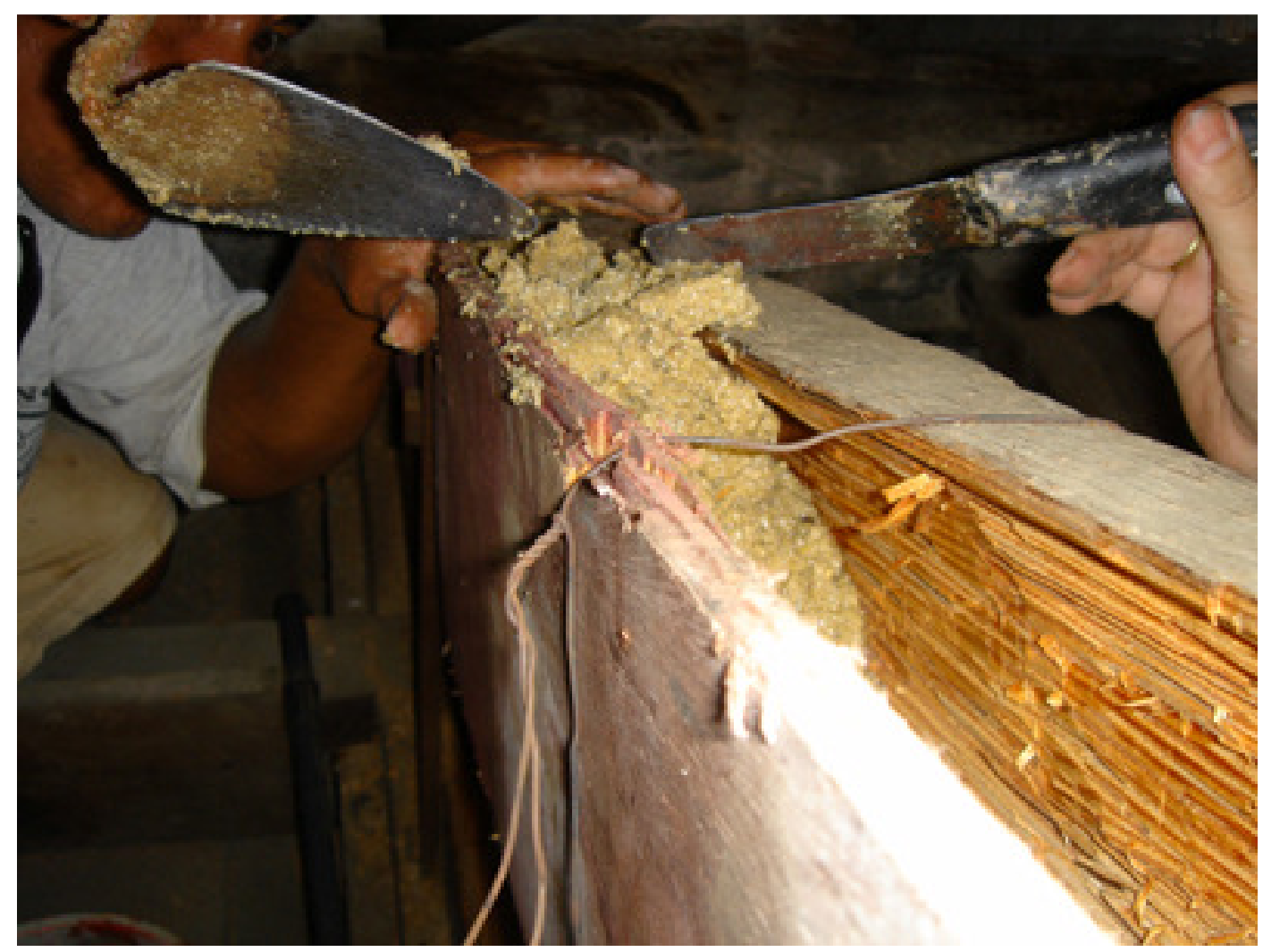

FIGURA 03 - Obturação das cavidades, Museu Villa-Lobos. Fotografia de Marisa Hoirisch, 2005.

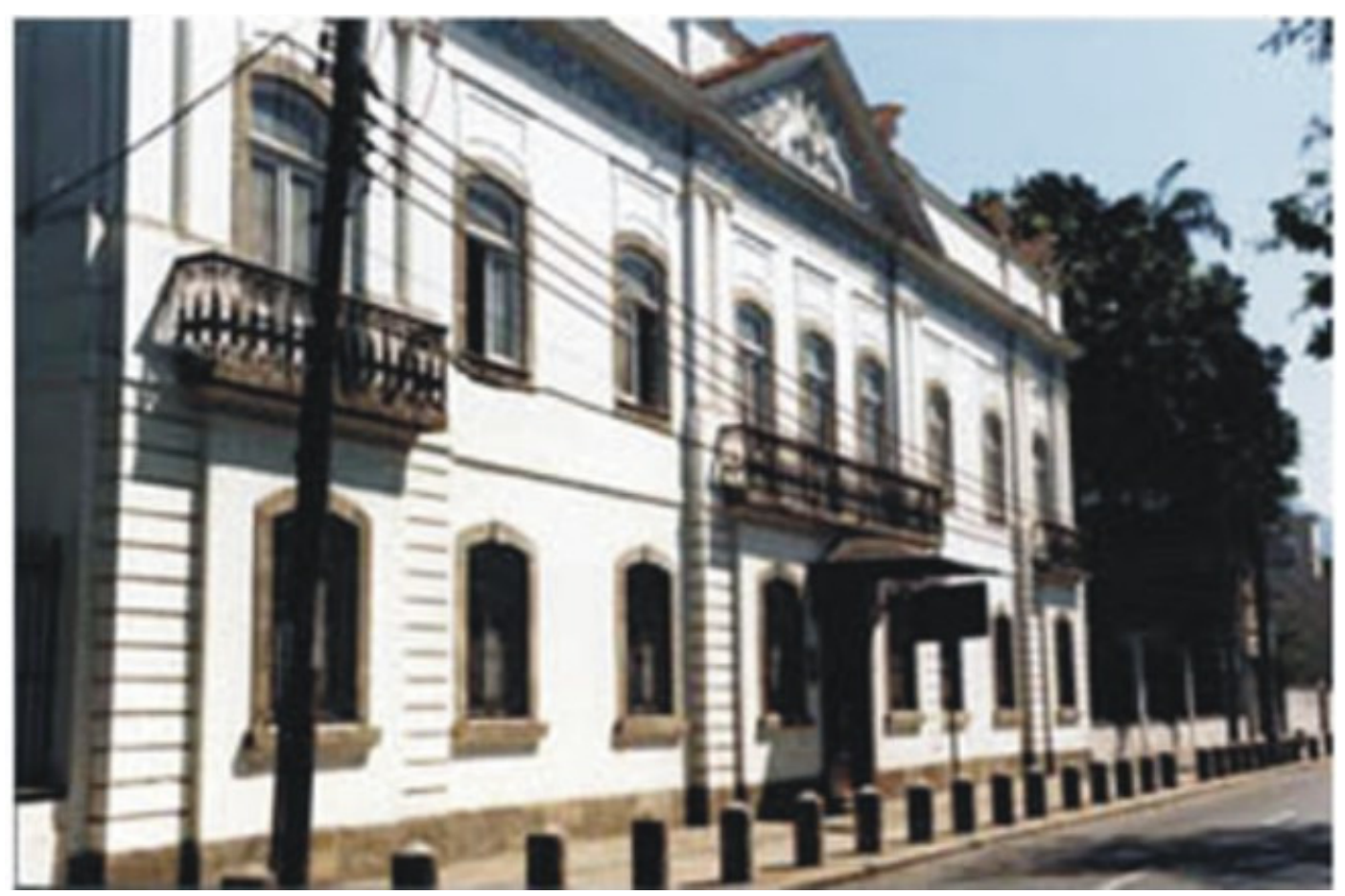

FIGURA 04 - Solar da Marquesa de Santos. Hoje, Museu do Primeiro Reinado. Fonte: http://wikimapia.org/6175830/pt/Museu-do-Primeiro-Reinado 


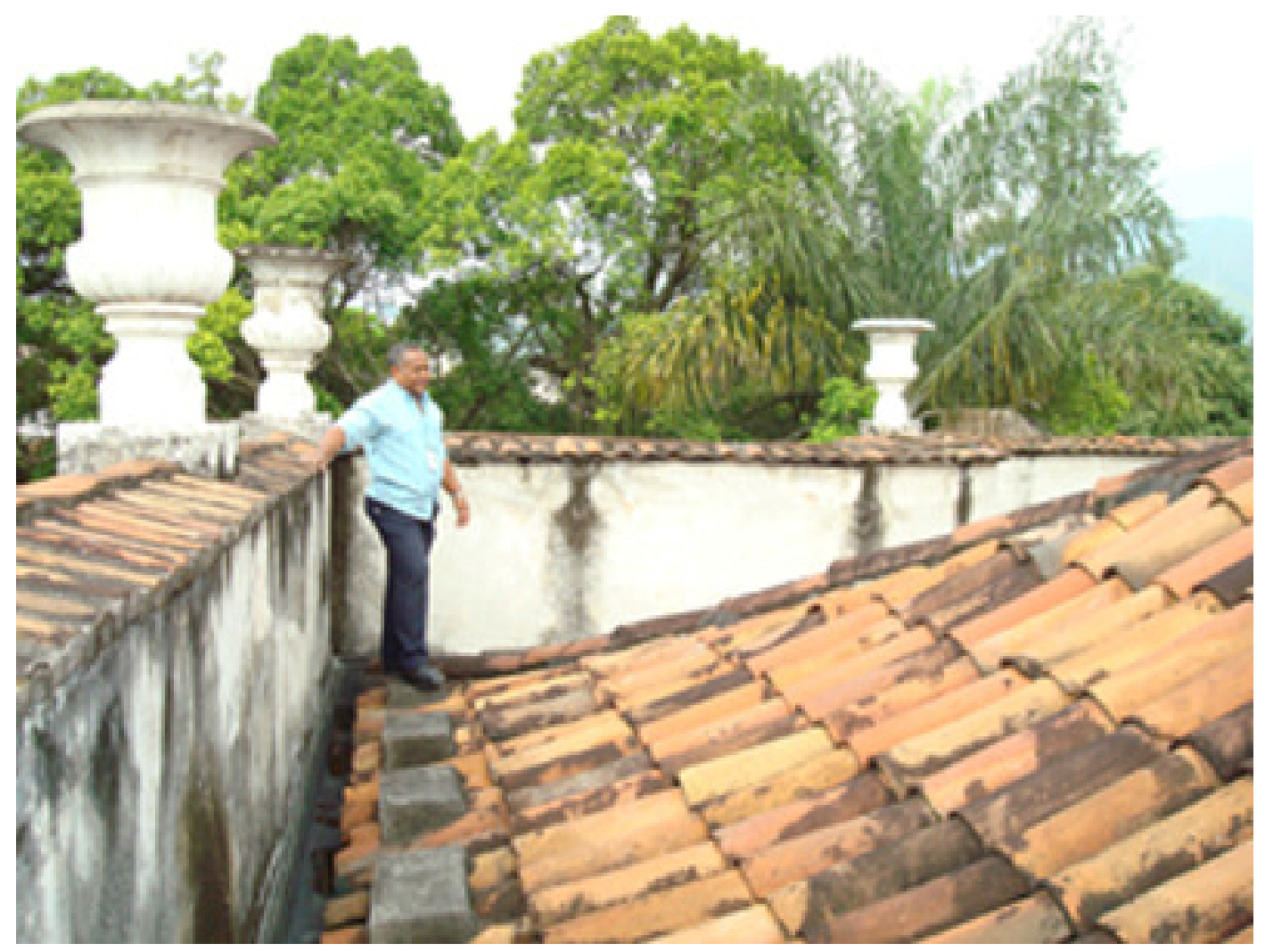

FIGURA 05 - Telhado do Museu do Primeiro Reinado. Fonte: Fotografia de Marisa Hoirisch.

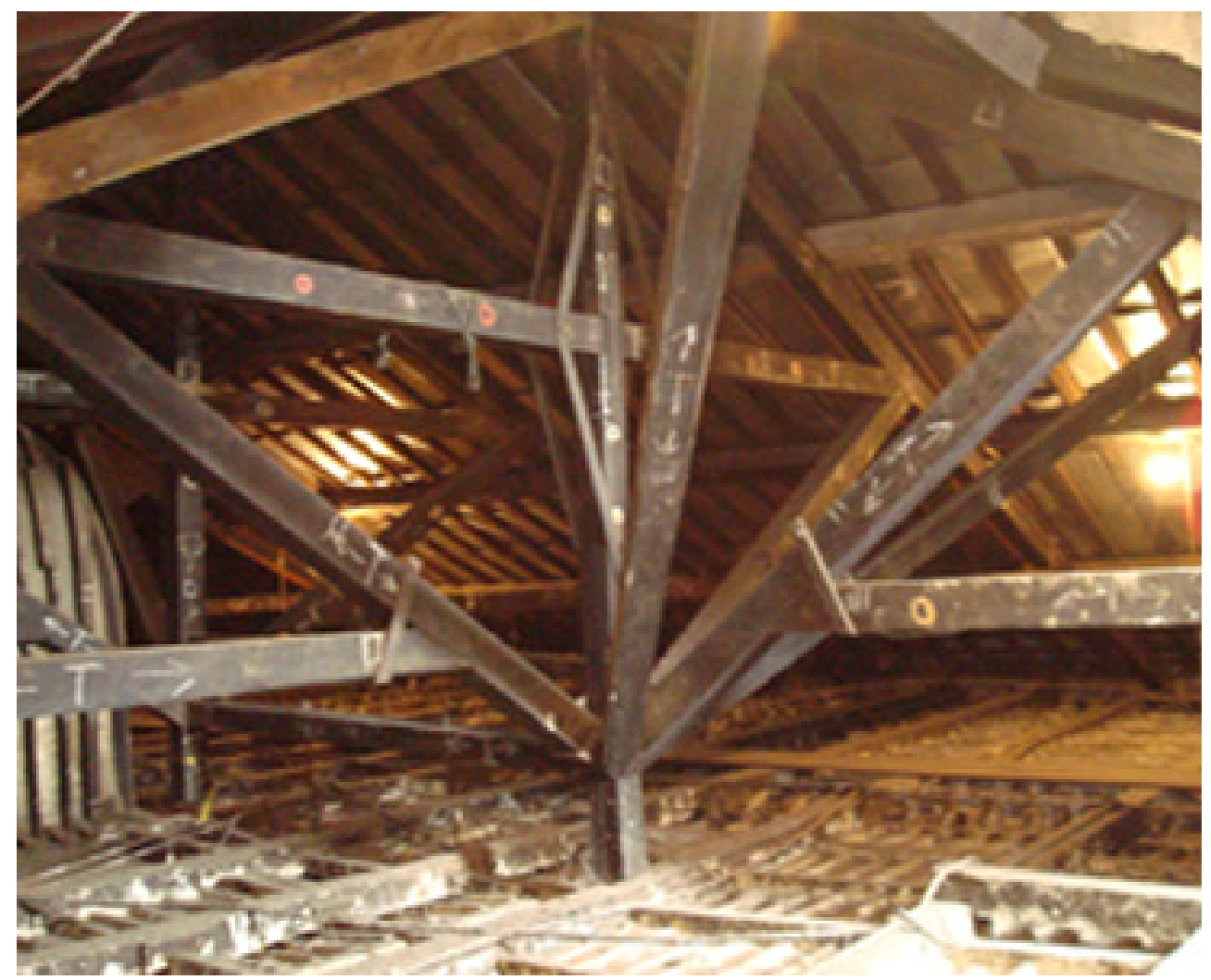

FIGURA 06 - Reforço em aço, Museu do Primeiro Reinado, 2008. Fotografia de Marisa Hoirisch. 


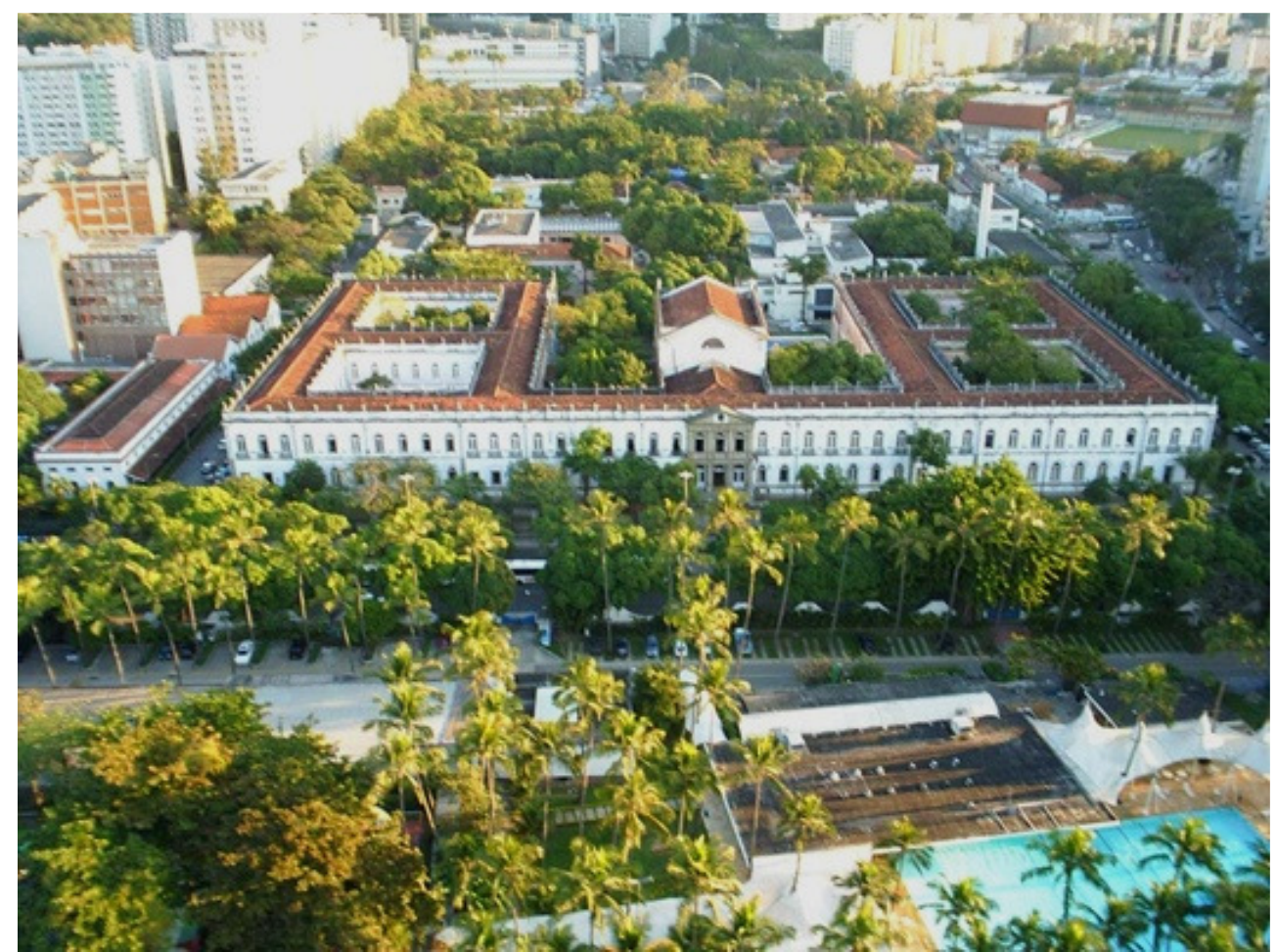

FIGURA 07 - Palácio Universitário, vista aérea, s/d. Fonte:

http://en.wikipedia.org/wiki/Federal_University_of_Rio_de_Janeiro

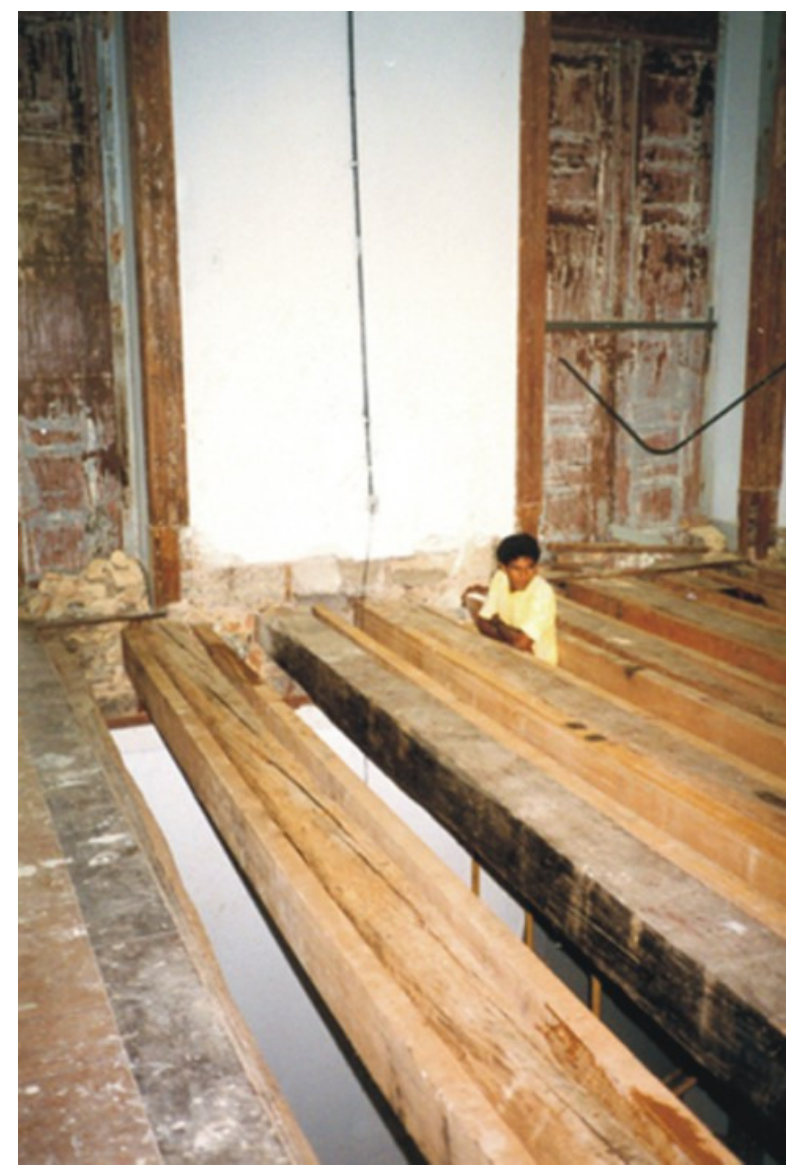

FIGURA 08 - Processo "sanduíche"no Palácio Universitário. Fotografia de Marisa Hoirisch, 1995. 


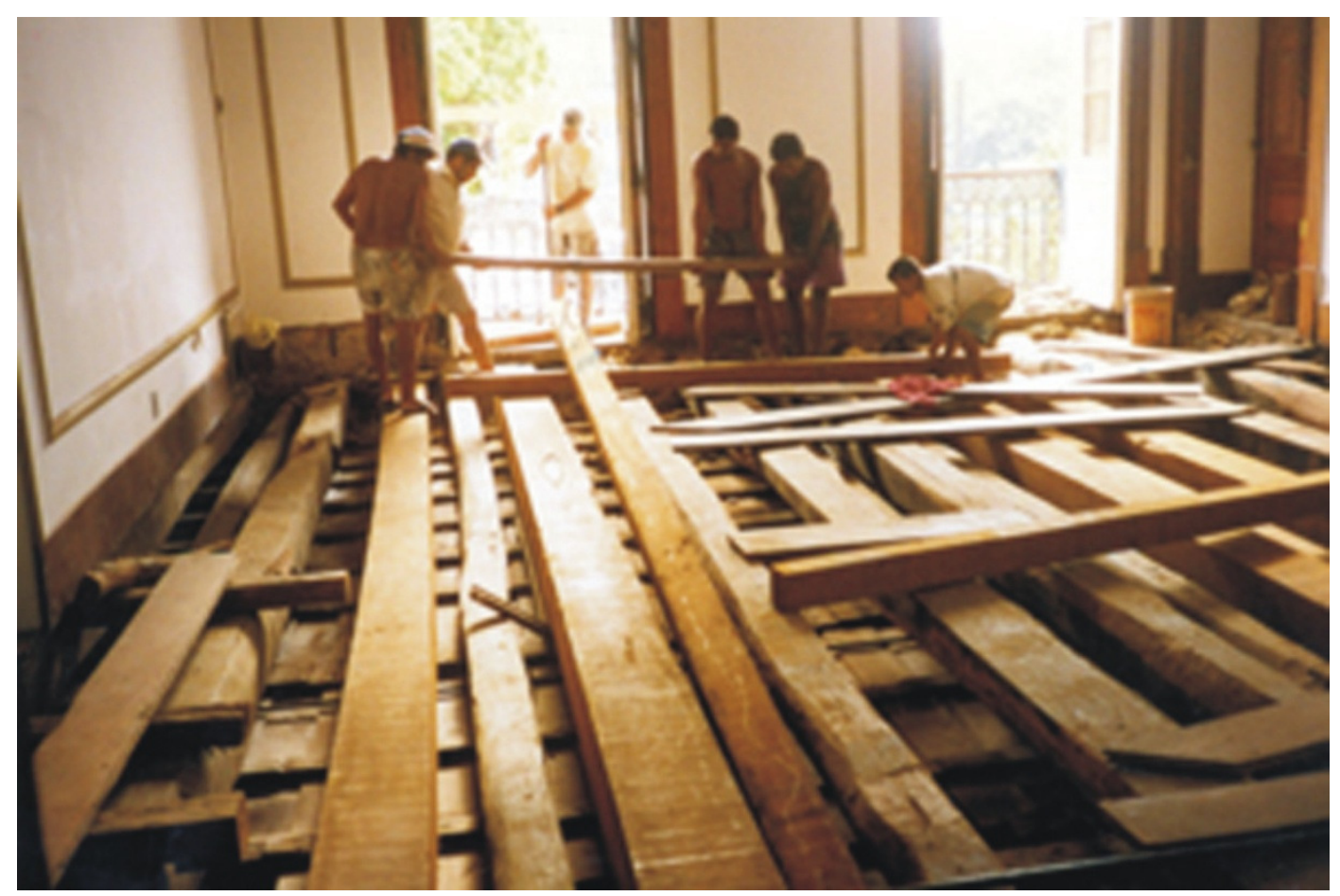

FIGURA 09 - Restauração do piso do Palácio Universitário. Fotografia de Marisa Hoirisch, 1996.

\section{Notas}

(1) Domitila de Castro Canto e Melo foi a Marquesa de Santos.

(2) O IPHAN foi criado pelo Decreto ํㅜㄹ, de 30 de novembro de 1937.

(3) O hiato se justifica, afinal, antes mesmo da desativação do Hospício de Pedro II, até 1944 estava nos planos do Ministro Capanema utilizar o prédio para abrigar o Externato do Colégio Pedro II. A ideia foi descartada em dezembro de 1945, quando se decidiu por seu uso pela Universidade do Brasil.

\section{Referências Bibliográficas}

CURY, Isabelle. (Org.). Cartas patrimoniais. 2. ed. rev. e aum. Rio de Janeiro: IPHAN, 2000.

HOIRISCH, Marisa. Restauração das estruturas de madeira em prédio histórico da Universidade Federal do Rio de Janeiro. In: INTERNATIONAL CONFERENCE ON THE BEHAVIOR OF DAMAGED STRUCTURES (DAMSTRUC), 4., 2005, João Pessoa. Anais...Niterói, RJ: UFF, 2005. p. 1159-1178.

HOIRISCH, Marisa. Palácio Universitário: materiais e técnicas construtivas. 2008. 213 p. Dissertação (Mestrado do Programa de Pós-Graduação em Arquitetura)-Faculdade de Arquitetura e Urbanismo da Universidade Federal do Rio de Janeiro, Rio de Janeiro, 2008. 
LIVRO de Tombo do Iphan. Disponível em: http://www2.iphan.gov.br/ans/inicial.htm. Acesso em: 26 ago.2008. http://www.museuvillalobos.org.br. Acesso em: 26 ago.2008.

MARQUES DOS SANTOS, Afonso Carlos. Entre a forma e o ideal: um emblema da civilização. In: CALMON, Pedro. O Palácio da Praia Vermelha. Rio de Janeiro: Editora UFRJ, 2004. Prefácio, p. 10.

RIEGL, Aloïs. El culto moderno a los monumentos: caracteres y origen. Madrid: Visor, 1999.

\section{Crédito}

* Doutoranda em Arquitetura pelo Programa de Pós-Graduação em Arquitetura da Faculdade de Arquitetura e Urbanismo da Universidade Federal do Rio de Janeiro (PROARQ/FAU/UFRJ) e-mail: marisahoirisch@gmail.com

** Doutora pelo Instituto Alberto Luiz Coimbra de Pós-graduação e Pesquisa de Engenharia (COPPE/UFRJ) e Professora Adjunta do Programa de Pós-Graduação em Arquitetura da Faculdade de Arquitetura e Urbanismo da Universidade Federal do Rio de Janeiro (PROARQ/FAU/UFRJ) e-mail: rosinatrevisan@gmail.com 